Résumés des conférences et travaux

\title{
Prosopographie des acteurs du livre
}

\section{Dominique Varry}

\section{(2) OpenEdition Journals}

Édition électronique

URL : https://journals.openedition.org/ashp/749

DOI : 10.4000/ashp.749

ISSN : 1969-6310

Éditeur

Publications de l'École Pratique des Hautes Études

\section{Édition imprimée}

Date de publication : 1 octobre 2009

Pagination : 313

ISSN : 0766-0677

\section{Référence électronique}

Dominique Varry, "Prosopographie des acteurs du livre », Annuaire de l'École pratique des hautes études (EPHE), Section des sciences historiques et philologiques [En ligne], 140 | 2009, mis en ligne le 21 octobre 2009, consulté le 06 juillet 2021. URL : http://journals.openedition.org/ashp/749; DOI : https://doi.org/ 10.4000/ashp.749 


\title{
PROSOPOGRAPHIE DES ACTEURS DU LIVRE
}

\author{
Chargé de conférences : M. Dominique VARRY
}

Programme de l'année 2007-2008 : I. Prosopographie des acteurs du livre. - II. Bibliographie matérielle.

Dans les années 2004-2007, le séminaire s'est attaché à faire découvrir aux auditeurs des exemples concrets rencontrés au cours de nos recherches sur le monde du livre, principalement au XVIII ${ }^{\mathrm{e}}$ siècle. Ces cas d'école ont ainsi permis d'étudier différentes caractéristiques de l'imprimé de l'époque artisanale, telles que le chercheur peut les rencontrer au cours de ses travaux.

Sans abandonner totalement cette approche, les séances de l'année 2007-2008 ont privilégié des thématiques conçues comme autant de « fiches techniques » sur les principales caractéristiques du livre imprimé ancien. Celles-ci permettront de préparer l'élaboration d'un manuel de bibliographie matérielle en français, qui pourrait être mis à disposition de la communauté scientifique sur le web, ce qui permettrait des corrections, adjonctions et améliorations constantes. Cet instrument comblerait une lacune, dans la mesure où l'essentiel de la littérature sur le sujet actuellement disponible est en anglais.

Les cinq séances de l'année ont porté sur les thèmes suivants : 19 novembre 2007 : Introduction générale à la bibliographie matérielle. - 21 janvier 2008 : la reconnaissance et l'identification des papiers anciens (formes interne et externe, techniques de relevé de filigranes, identification et datation de filigranes). - 18 février 2008 : les formats du livre ancien (détermination des formats des plus courants aux plus rares et petits). - 14 avril 2008 : le système des permissions du sceau (privilèges du roi, permissions tacites, permissions simples, « impressions tolérées »). — 19 mai 2008 : l'utilisation de la fausse adresse « Londres » au XVIII ${ }^{\mathrm{e}}$ siècle. 